\title{
A Possible Role of Nitric Oxide Formation in the Vasodilatation of Rabbit Ear Artery Induced by a Topically Applied Capsaicin Analogue
}

\author{
Tadahiko SUZUKI, Shohji WADA, Nobuyuki TOMIZAWA ${ }^{1)}$, Ryo KAMATA, Sin-ya SAITO, Itaru SATO2), \\ Etsuko SUGAWARA ${ }^{3)}$, Eiichi TACHIKAWA ${ }^{4)}$ and Haruo KOBAYASHI \\ Departments of Veterinary Pharmacology, ${ }^{I}$ Veterinary Surgery and ${ }^{2}$ Veterinary Public Health, Faculty of Agriculture, ${ }^{3}$ Food Science \\ Laboratory, Faculty of Education, Iwate University, 3-18-8 Ueda, Morioka, Iwate 020-8550, and ${ }^{4}$ Department of Pharmacology, \\ School of Medicine, Iwate Medical University, 19-1 Uchimaru, Morioka, Iwate 020-8505, Japan
}

(Received 11 July 1997/Accepted 7 January 1998)

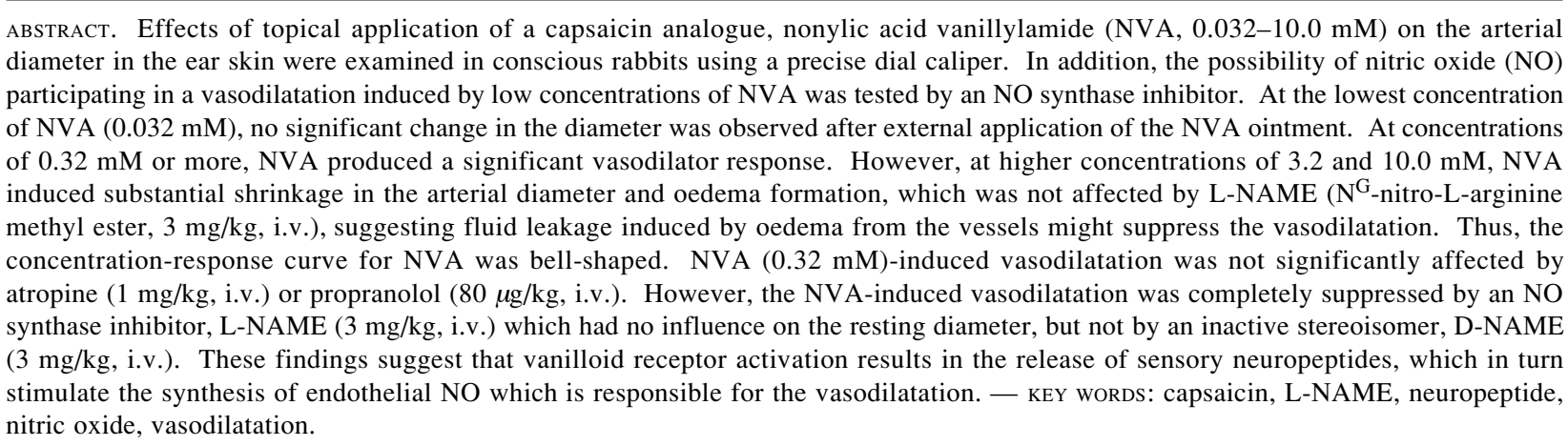

Capsaicin (Fig. 1) is an active substance responsible for the irritating and pungent effects of hot peppers (paprika, Hungarian red pepper, Capsicum annuиm L.). Nonylic acid vanillylamide (NVA) is a very stable synthetic capsaicin analogue (Fig. 1), which lacks a $\mathrm{C}=\mathrm{C}$ bond in the aliphatic side chain, and is a constituent of counterirritant preparations on the market. Capsaicin and NVA are both useful for producing counterirritation $[11,20]$. It is now known that capsaicin-like molecules affect $\mathrm{C}$-fiber, thin primary afferent neurons that are connected to distinct sensory receptors $[2$, 5, 10, 11, 16, 17, 26, 28, 29, 54, 55].

Capsaicin has highly specific actions on polymodal nociceptors $[16,18]$, which are exerted via a specific membrane receptor (vanilloid receptor) whose activation increases membrane cation permeability and which can be distinguished by the competitive antagonist capsazepine [12, $13,18,50]$ or the polyvalent dye ruthenium red [8, 14]. This mechanism of activation accounts for the burning pain sensation that capsaicin induces after topical application to the skin [9]. In addition, chemical or electrical stimulation of sensory nerves in the skin causes an inflammatory reaction comprising arteriolar dilatation, increase in venular permeability and recruitment of leukocytes [10, 28, 42]. This 'neurogenic inflammation' arises from the release of vasoactive peptide transmitters such as substance $\mathrm{P}$ and calcitonin gene-related peptide (CGRP) from the peripheral endings of fine afferent nerve fibres [23, 31, 38, 39, 41, 58]. Following activation, however, capsaicin induces sensory neurons to become inexcitable; consequently, noxious stimuli are no longer effective. The complexity of capsaicininduced responses of sensitization and desensitization can often lead to confusion in the interpretation of the capsaicin action [29].

Tissue blood flow is regulated by local autoregulatory mechanisms, factors released from endothelial cells, hormones and neural factors. The role of autonomic neurons, notably of sympathetic vasoconstrictor neurons, is well studied [30]. However, even after blockade of<smiles>COc1cc(CNC(=O)CCCCC=CC(C)(C)C(Cl)(Cl)Cl)ccc1O</smiles><smiles>CCCCCCCCCC(=O)NCc1ccc(O)c(OC)c1</smiles>

Fig. 1. Chemical structures of capsaicin and nonylic acid vanillylamide (NVA). 
cholinergic and noradrenergic transmission, blood vessels can actively be dilated in response to nerve stimulation. The nonadrenergic noncholinergic (NANC) vasodilator neurons have long eluded identification, but there is now good evidence that NANC vasodilatation in many vascular beds is mediated by nerve fibers that utilize peptides such as substance $\mathrm{P}$ (SP) and calcitonin gene-related peptide (CGRP) as their transmitters [30]. The possibility remains that the neurotransmitters from the afferent nerve fibers control the vascular effector system via the release of vasoactive messenger molecules from endothelial cells. The major endothelium-derived relaxing factor is nitric oxide (NO), which is synthesized from L-arginine by the activity of a constitutive NO synthase in the endothelial cells [45]. Endothelium-derived NO participates in the vasodilator action of substance $\mathrm{P}[19,49,57]$ and CGRP [22, 24, 25, $31,32,49]$. Therefore, in the present study, it was investigated whether NO participates in the capsaicininduced vasodilator response in the rabbit ear skin. The involvement of $\mathrm{NO}$ was examined with $\mathrm{N}^{\mathrm{G}}$-nitro-L-arginine methyl ester (L-NAME), an inhibitor of the constitutive NO synthase [21, 46, 47]. The inactive enantiomer, D-NAME was given in the control experiments. Some of this work has already been presented in preliminary form [51, 52].

\section{MATERIALS AND METHODS}

Animals: Japanese White rabbits of either sex with an average weight of $2.5-3.5 \mathrm{~kg}$ were used. About a week before each experiment, the rabbit ear skin was shaved and depilated. All experiments were carried out in a quiet room at a thermo-neutral temperature of $22-24^{\circ} \mathrm{C}$ in which direct air flow was prevented from falling on and affecting the animals who were conscious and comfortably housed in portable animal cages.

Measurement of blood vessel diameter: In the present study, changes in the diameter of the rabbit ear artery were directly measured to reveal the effects of capsaicin analogue on the blood vessel, according to a technique described previously [51-53]. In brief, the normal resting diameter of the ear artery was measured by precise dial calipers (Tajima, Japan). Following this assessment of each animal, various concentrations of NVA in an inert ointment base were applied to a circular area, approximately $7 \mathrm{~cm}^{2}$, on the surface of the ear skin and the arterial diameter of the artery was measured during the experimental period. When NVAinduced oedema formation was observed, the blood vessel area (red zone), but not the oedema area (white zone), was measured to obtain the net diameter of the vessels.

The next series of experiments were carried out to examine the pharmacological characteristics of this acute capsaicin response in more detail. Following assessment of the resting diameter, various antagonists were injected into the ear vein before a topical application of suprathreshold concentration of NVA $(0.32 \mathrm{mM})$. Resultant diameter changes were monitored as above with dial calipers.

Measurement of oedema formation: Formation of oedema in the rabbit ear skin was measured by a scoring test where the extent of oedema formation around artery are represented in increasing order as follows: -, no effect; +, weak; ++, remarkable. In the L-NAME experiment, L-NAME (3 mg/ $\mathrm{kg}$, i.v.) was injected into the ear vein $3 \mathrm{~min}$ before a topical application of suprathreshold concentration of NVA $(0.32$ $\mathrm{mM})$. Resultant pathological changes were monitored using the scoring test.

Drugs: The following drugs were used: NVA (Chemie Linz), atropine sulfate (Nakarai Tesque), DL-propranolol hydrochloride (Nakarai Tesque), L-NAME (Wako), DNAME (Wako). NVA was mixed with an inert ointment base ( $5 \%$ polyethylene $+95 \%$ liquid paraffin). Atropine, propranolol, L-NAME and D-NAME were dissolved in saline.

Statistical analysis: All data are presented as mean \pm SEM. Statistical significance evaluation of the results were performed with Student's $t$-test, Welch's test, paired $t$-test or Tukey's multiple test. $\mathrm{P}<0.05$ was considered significant.

\section{RESULTS}

Effects of NVA on the vessel diameter: In the first series of experiments, arterial diameters of rabbit ear skin were measured, before and after acute topical application of NVA ointment at varying concentrations. Figure 2 shows timecourse changes in average response from the baseline diameters. At the lowest concentration of $0.032 \mathrm{mM}$, no change in the diameter compared to the matched control ointment base was observed after the exposure to NVA ointment. At concentration of $0.32 \mathrm{mM}$, NVA produced an initial slight and transient vasoconstrictor response of the artery, followed by a prolonged vasodilator response which

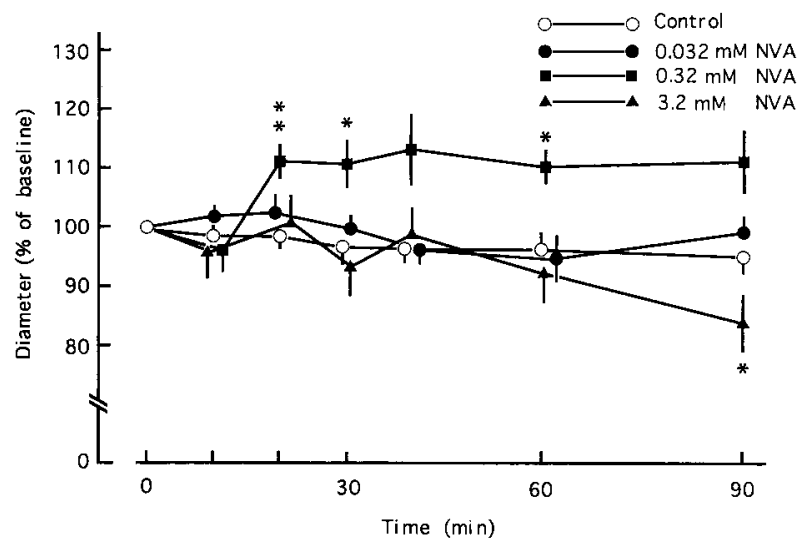

Fig. 2. Percentage change in diameter of ear artery in response to varying concentrations of topical NVA in conscious rabbits. NVA ointment was applied topically to the ear in concentrations of $0(\bigcirc), 0.032(\mathbf{O}), 0.32(\boldsymbol{\square})$ and $3.2 \mathrm{mM}($ $\boldsymbol{\Delta})$. Baseline diameters were measured with a precise dial caliper before drug application. Data are expressed as percentage of baseline diameter. Each point is the mean \pm SEM (vertical bars) of five animals. $* \mathrm{P}<0.05$ and $* * \mathrm{P}<0.01$, as compared to control ointment base by paired $t$ test. Baseline diameters (mean \pm SEM in $\mathrm{mm}$ ) were $1.43 \pm 0.07$ $(\mathrm{n}=20)$. 
Table 1. Effect of L-NAME on the NVA-induced oedema formation in the rabbit ear skin

\begin{tabular}{|c|c|c|c|c|c|c|}
\hline \multicolumn{2}{|r|}{ Drug } & \multirow{3}{*}{$\begin{array}{l}\text { Degree } \\
\text { of } \\
\text { oedema }\end{array}$} & \multicolumn{4}{|c|}{ Number (\%) of animals showing the responses } \\
\hline \multirow{2}{*}{$\begin{array}{l}\text { NVA } \\
(\mathrm{mM})\end{array}$} & \multirow{2}{*}{$\begin{array}{c}\text { L-NAME } \\
\text { (mg/kg, i.v.) }\end{array}$} & & \\
\hline & & & 0 & 15 & 30 & 60 \\
\hline COB & PSS & - & $3(100)$ & $3(100)$ & $3(100)$ & $3(100)$ \\
\hline 1.0 & PSS & - & $3(100)$ & $3(100)$ & $3(100)$ & $3(100)$ \\
\hline \multirow[t]{2}{*}{3.2} & PSS & - & $3(100)$ & $3(100)$ & & \\
\hline & & + & & & $3(100)$ & $3(100)$ \\
\hline \multirow[t]{2}{*}{10.0} & PSS & - & $3(100)$ & $3(100)$ & & \\
\hline & & ++ & & & $3(100)$ & $3(100)$ \\
\hline COB & 3.0 & - & $3(100)$ & $3(100)$ & $3(100)$ & $3(100)$ \\
\hline 1.0 & 3.0 & - & $3(100)$ & $3(100)$ & $3(100)$ & $3(100)$ \\
\hline \multirow[t]{2}{*}{3.2} & 3.0 & - & $3(100)$ & $3(100)$ & & \\
\hline & & + & & & $3(100)$ & $3(100)$ \\
\hline \multirow[t]{2}{*}{10.0} & 3.0 & - & $3(100)$ & $3(100)$ & & \\
\hline & & ++ & & & $3(100)$ & $3(100)$ \\
\hline
\end{tabular}

COB: Control ointment base. PSS: Physiological salt solution. Symbols: -, No effect; +, Weak; ++, Remarkable.

reached a maximum usually 20-60 min after the exposure to NVA. However, no such vasodilator response was observed after exposure to the highest concentration of NVA $(3.2 \mathrm{mM})$ and, in fact, substantial shrinkage in the diameter was observed $90 \mathrm{~min}$ after the exposure to NVA at this concentration. This shrinkage was almost coincident with oedema formation, which was detectable with concentrations of NVA above $3.2 \mathrm{mM}$ (Table 1 ).

Figure 3 shows the concentration $(0.032-10.0 \mathrm{mM})$ response curves for NVA obtained 30 (upper curve) and 60 (lower curve) min after the drug application. These concentration curves were bell-shaped and the threshold concentration of NVA for the vasodilator response 30 or 60 min after topical application seemed to be around $0.1 \mathrm{mM}$ (Fig. 3), indicating that rabbit ear skin is, to a considerable extent, sensitive to the vasodilator effect of capsaicin.

NVA-induced oedema formation: At the concentration of $1.0 \mathrm{mM}$, no change around the artery compared to the matched control ointment base was observed after the exposure to the ointment. At concentrations of 3.2 and 10 $\mathrm{mM}$, dose-dependent formations of oedema induced by NVA were observed 30 or 60 min after the application of NVA (Table 1).

Effect of L-NAME on the resting artery and NVA-induced oedema formation: L-NAME ( $3 \mathrm{mg} / \mathrm{kg}$, i.v.) had no effect on the resting vessels. Furthermore, compared with the formation measured in the rabbit treated with control physiological salt solution, L-NAME did not alter the course of the NVA-induced oedema formations in the rabbit ear skin (Table 1), indicating that nitric oxide is not involved in oedema formation under these conditions.

Effects of atropine on NVA-induced vasodilatation: In the second series of experiments, the prolonged vasodilator response to $0.32 \mathrm{mM}$ NVA has been characterized with various pharmacological agents. Figure 4 shows the effects of pretreatment of muscarinic acetylcholine (ACh) receptor antagonist, atropine $(1 \mathrm{mg} / \mathrm{kg}$ i.v.) on the resting and NVA

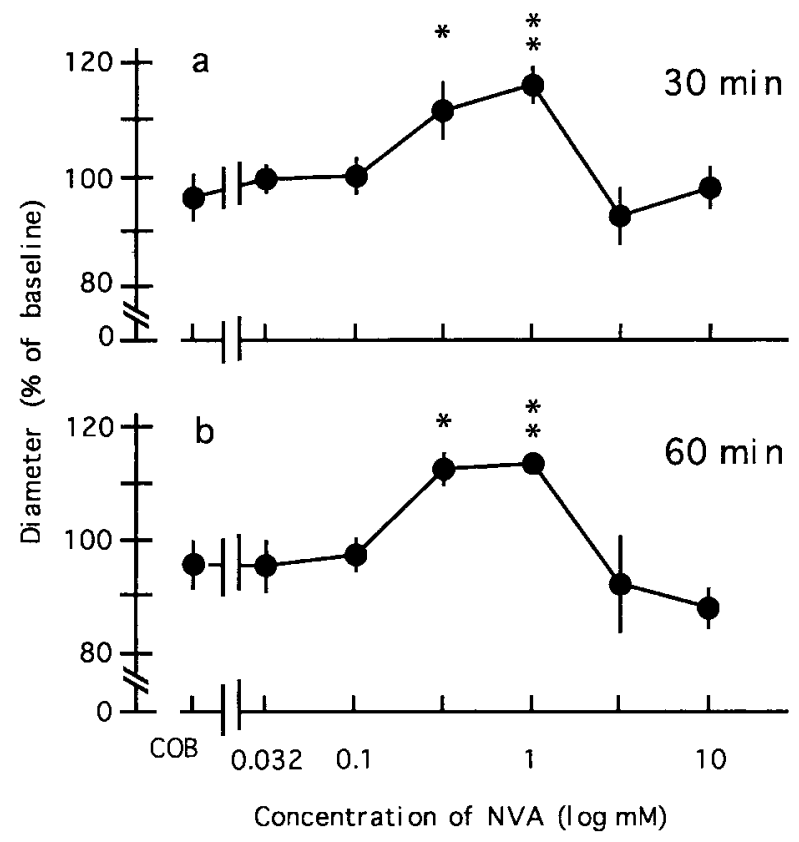

Fig. 3. Dose-related vasodilative effects of NVA on the diameter of the ear artery in conscious rabbits. NVA ointment was applied topically to the ear skin in concentrations of $0.032-10.0 \mathrm{mM}$. The responses to NVA were plotted as percentage of baseline diameter vs log concentration of NVA 30 (a) or 60 (b) min after application. Each point is the mean \pm SEM (vertical bars) of five animals. ${ }^{*} \mathrm{P}<0.05$ and ${ }^{*} * \mathrm{P}<0.01$, as compared to control ointment base (COB) by Student's $t$ test.

(0.32 $\mathrm{mM})$-induced vasodilative ear artery. In this experiment, rabbits were given atropine $3 \mathrm{~min}$ before the NVA application and the vessel diameters were measured before and $30 \mathrm{~min}$ after the NVA application. Although the resting and NVA-induced vasodilative vessels were slightly inhibited by atropine, these inhibitory effects were not 


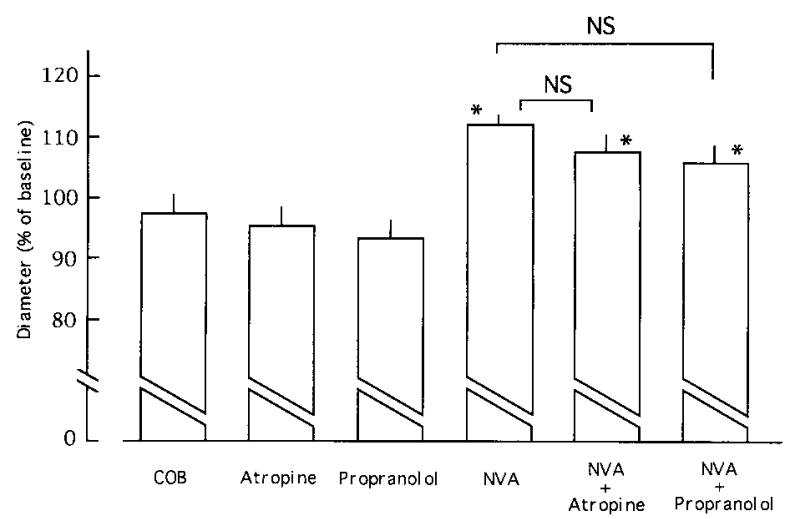

Fig. 4. The effects of pretreatment of atropine $(1 \mathrm{mg} / \mathrm{kg}$, i.v. $)$ and propranolol $(80 \mu \mathrm{g} / \mathrm{kg}$, i.v.) on vasodilator response to topical NVA $(0.32 \mathrm{mM})$ in the ear artery of conscious rabbits. Rabbits were given atropine or propranolol $3 \mathrm{~min}$ before the application of NVA. Vessel diameters were measured with precise dial caliper before and $30 \mathrm{~min}$ after NVA application. Each column represents percentage of baseline diameter with SEM shown by the vertical bars $(n=5)$. Data were analysed by Tukey's multiple test. NS=not significant; $* \mathrm{P}<0.05$, as compared to control ointment base (COB).

specific for NVA-induced vasodilatation, and were not statistically significant.

Effects of propranolol on NVA-induced vasodilatation: Figure 4 also shows the effect of pretreatment of adrenergic $\beta$ receptor antagonist, propranolol $(80 \mu \mathrm{g} / \mathrm{kg}$, i.v.) on the resting and NVA $(0.32 \mathrm{mM})$-induced vasodilative artery. In this experiment, rabbits were given propranolol $3 \mathrm{~min}$ before the NVA application and the vessel diameters were measured before and $30 \mathrm{~min}$ after the NVA application. Although the resting and NVA-induced vasodilative vessels were slightly inhibited by propranolol, these inhibitory effects were not specific for NVA-induced vasodilatation, and were not statistically significant.

Effects of L-NAME and D-NAME on NVA-induced vasodilatation: Figure 5 shows effects of a low dosage of L-NAME, which suppresses the formation from L-arginine to L-citrulline, on the resting and NVA $(0.32 \mathrm{mM})$-induced vasodilative ear artery. The vasodilator response to topical NVA was completely suppressed by L-NAME (3 mg/kg, i.v.), while the resting diameter of the artery was not affected by L-NAME. Furthermore, the inactive stereoisomer DNAME (3 mg/kg i.v.) did not affect the NVA-induced vasodilator response, indicating that the NVA-induced vasodilatation is dependent on the formation of NO.

\section{DISCUSSION}

The present study has shown that NVA induces vasodilator effects on the artery of rabbit ear skin and that the vasodilator response to low concentrations of NVA was completely suppressed by the NO synthase inhibitor [21, 22, 46, 47], L-NAME (Fig. 5), but not the inactive stereoisomer, D-NAME (Fig. 5). These results strongly suggest a possible role of nitric oxide formation in the

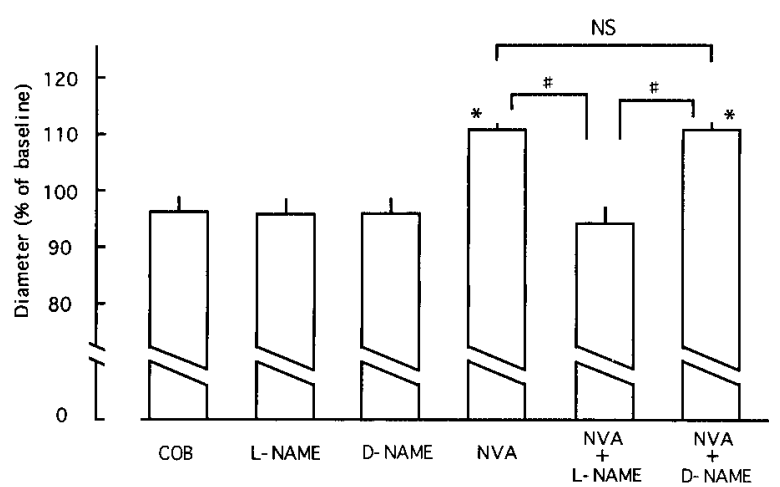

Fig. 5. Inhibitory effect of pretreatment of $\mathrm{N}^{\mathrm{G}}$-nitroL-arginine methyl ester (L-NAME) on vasodilator response to topical NVA in the artery of conscious rabbits. Rabbits were given L-NAME $(3 \mathrm{mg} / \mathrm{kg}$, i.v.) or $\mathrm{N}^{\mathrm{G}}$-nitro-D-arginine methyl ester (DNAME, $3 \mathrm{mg} / \mathrm{kg}$, i.v.) $3 \mathrm{~min}$ before the application of NVA. Vessel diameters were measured with precise dial caliper before and $30 \mathrm{~min}$ after NVA application. Each column represents percentage of baseline diameter with SEM shown by the vertical bars $(n=5)$. Data were analysed by Tukey's multiple test. $\mathrm{NS}=$ not significant; $* \mathrm{P}<0.05$, as compared to control ointment base (COB). "P $<0.05$, as compared to NVA + L-NAME group.

vasodilatation induced by topical NVA. At high concentrations of NVA, however, it was observed that NVA produced substantial shrinkage in the diameter (Fig. 2). This shrinkage was almost coincident with oedema formation, which was detectable with concentrations of NVA above $3.2 \mathrm{mM}$ (Table 1). Substance P and CGRP, which all increase in the vascular permeability leading to oedema formation [56], are considered to be the principal mediators of neurogenic inflammation in the skin. In the present experiments, unlike the vasodilator component, the exudative component of the neurogenic inflammatory response to NVA was not affected by L-NAME. Although it is known that protein leakage induced by substance $\mathrm{P}$ involves endothelium-derived NO, which may add to the leakage of plasma protein and fluid [34], Lippe et al. [40] reported that the exudative component of the neurogenic inflammatory response to mustard oil, which stimulates capsaicin sensitive afferent neurons, does not seem to involve NO directly. Thus, it is possible that nitric oxide was not involved in the NVA-induced oedema formation in the present study, although the possibility remains that the L-NAME used was not sufficient to suppress the oedema formation since a low dose of L-NAME was used in the present experiments. Also, it is feasible that the leakage of fluid from blood vessels to interstitional space induced by oedema formation [40] might suppress the NVA-induced vasodilator response and then produce substantial shrinkage in the diameter, since, except for the swollen parts of vessels, only the net diameter of vessels was measured in the present experiment. 
There are considerable species differences in the sensitivity of afferent neurons to capsaicin [28, 29]. It has been said that the rabbit is less sensitive to capsaicin analogues, although no systematic investigation has been done [28, 29]. Our results show that threshold concentration of NVA to the rabbit ear skin is $0.032-0.1 \mathrm{mM}$ from changes in the blood vessel diameters (Fig. 3). Roberts et al. [48] reported that the threshold concentration of capsaicin to the human skin is $0.033-0.16 \mathrm{mM}$ by laser Doppler blood flux [48]. Since it has been reported that the rabbit ear artery is innervated by capsaicin-sensitive peptidergic afferent neurons [44], it thus seems likely that sensory neurons in the skin of humans and rabbits are similarly sensitive to the vasodilator effect of topical capsaicin analogue, although it is difficult to compare the extent of vasodilator responses measured by these different methods.

In the rabbit, intradermal injection of capsaicin induces a vasodilator response [6-8] which is inhibited by the CGRP antagonist $\mathrm{CGRP}_{(8-37)}[31,32]$. This suggests that CGRP is the important vasodilator neuropeptide which is released from capsaicin-sensitive nerves in skin. It is well known that substance $\mathrm{P}$ is often co-localized with CGRP in capsaicin-sensitive nerves. However, substance $\mathrm{P}$, despite established potent vasoactive effects in rat skin [38], is extremely weak when injected intradermally into the rabbit $[4,5]$ and a selective neurokinin-1 antagonist [3] had no effect on capsaicin-induced blood flow in rabbit skin [33]. Thus, it is quite possible that NVA-induced vasodilatation of rabbit ear skin is attributable to CGRP, but not substance $P$, released from sensory neurons, since recent studies suggest that CGRP is an important mediator of arteriolar dilatation whilst substance $\mathrm{P}$ is an essential mediator of increased vascular permeability [23, 31, 38, 39, 41, 58].

Our results that the resting and NVA-induced vasodilative vessels were slightly inhibited by atropine suggest that there may be some role of $\mathrm{ACh}$ in regulation of artery tone in vivo. However, these inhibitory effects were not significant (Fig. 4). The present result is consistent with earlier findings that atropine fails to block, and eserine fails to potentiate, antidromic vasodilatation in the rabbit ear [27]. It is thus unlikely that ACh is a major mediator of capsaicin sensitive nerve-mediated vasodilatation induced by the suprathreshold concentration of NVA. In the present study, a tendency to inhibition of the resting and NVA-induced vasodilative vessels by adrenoceptor $\beta_{1,2}$-receptor antagonist, propranolol, was observed. Similar results were obtained from extensive experiment in which the effect of pretreatment of the specific adrenoceptor $\beta_{2}$-receptor antagonist, ICI 118551 on the NVA-induced vasodilator response was investigated $[51,52]$. This suggests that the tendency to inhibit the resting and NVA-induced vasodilative artery may be attributable to action of the $\beta_{2^{-}}$ receptor antagonist, and that noradrenaline may have some role in regulation of artery tone in vivo. However, the inhibitory effect of propranolol or ICI 118551 was not specific for NVA-induced vasodilatation and it may thus be necessary to subtract the effect of propranolol or ICI 118551 on the resting diameter from that on NVA-induced vasodilative artery. The mechanism of NVA-induced vasodilatation, therefore, remains unexplained. However, the NVA-induced vasodilator response was completely suppressed by L-NAME (Fig. 5), a nitric oxide synthase inhibitor [21, 22, 46, 47], but not by an inactive stereoisomer, D-NAME (Fig. 5). The finding that the action of L-NAME on the vasodilative artery was enantiomerspecific indicates this drug acts by inhibition of the L-arginine: NO pathway [45, 47]. Furthermore, this concentration of L-NAME we used had no influence on the resting diameter (Fig. 5). Therefore, it is concluded that the L-arginine: NO pathway is specifically involved in capsaicin induced vasodilatation. It is thus conceivable that NVAinduced vasodilatation may be produced by NO formed either in the capsaicin sensitive sensory neuron or vascular endothelial cell, although the current investigation cannot discriminate between these possibilities.

Capsaicin has highly specific actions on polymodal nociceptive neurons $[6-8,13,50]$. This involves membrane depolarization and the opening of a unique, cation-selective, ion channel which can be selectively and competitively antagonized by capsazepine [13, 18, 43, 50]. Furthermore, it has been demonstrated that the functional capsaicin receptor antagonist, ruthenium red [8, 14], completely suppressed the vasodilator response to the topical capsaicin analogue [51, 52]. These data suggest that the NVA-induced vasodilator response may be mediated by a capsaicin receptor on polymodal nociceptive neurons in the rabbit ear skin. On the other hand, Hughes and Brain [31] reported that capsaicin-induced vasodilator response was totally inhibited by the CGRP antagonist, $\mathrm{CGRP}_{(8-37)}$. Moreover, they reported that L-NAME has an inhibitory effect on the increased blood flow induced by CGRP, especially at lower doses of CGRP [32]. It is known that CGRP can act via a selective rise in levels of cyclic AMP to induce vascular relaxation [24, 37]; or, in the rat aorta where L-NAME inhibits CGRP-induced relaxation [25], CGRP can act via an endothelial, nitric oxide-dependent mechanism to cause vascular relaxation $[5,24,25]$. This dual mechanism of vasodilator action of CGRP is in keeping with the finding that the hypotensive response to intravenous CGRP in the rat can be partially attenuated by nitric oxide synthase inhibitors [1, 22]. Hence, based on our results and analysis of the literature, it seems likely that in the rabbit ear skin there is a cascade of events in which vanilloid receptor activation induced by NVA results in the release of the sensory neuropeptides, such as CGRP, which in turn stimulate endothelial NO which is responsible for the observed arterial vasodilatation, although the effect of NVA on the membrane receptor was not investigated in the present experiments. Alternatively, NO might be involved in sensory-motor neuromodulation of sympathetic vasoconstriction by CGRP in the rabbit central ear artery, since such a hypothesis has been proposed for the artery [44].

The present study provides additional important evidence 
that with low suprathreshold doses of NVA, but not with higher doses, desensitization to NVA did not take place. These data suggest that the extent to which desensitization to capsaicin analogues develops is related to the dose of the drug, as well as the time of exposure to the drug, and the time interval between consecutive dosings [28]. It is known that, with low suprathreshold doses of capsaicin analogues given at appropriate intervals, desensitization does not necessarily occur so that excitation of thin sensory neurons $[35,36]$, pain reactions $[15,16,26,54,55]$, and peptide release from peripheral sensory nerve endings [2, 17] can be reproduced. Also, it may be possible that NVA-induced release of NO from endothelial cells could be reproduced with each application of low dose of this agent. The complexity of capsaicin-induced responses of sensitization and desensitization appears to limit the usefulness of capsaicin as a constituent of the classical counterirritant, or as a new analgesic for an attenuation of neurogenic inflammation [18] in clinical use [30], however, the application technique with low suprathreshold doses of capsaicin analogues given at appropriate intervals, may release capsaicin from the limitation of usefulness in clinical use [53].

\section{REFERENCES}

1. Abdelrahman, A., Wang, Y.-X., Chang, S. D. and Pang, C. C. Y. 1992. Mechanism of the vasodilator action of calcitonin gene-related peptide in conscious rats. Br. J. Pharmacol. 106: $45-48$.

2. Amann, R. 1990. Desensitization of capsaicin-evoked neuropeptide release-influence of $\mathrm{Ca}^{2+}$ and temperature. Naunyn-Schmiedeberg's Arch. Pharmacol. 342: 671-676.

3. Beresford, I. J. M., Birch, P. J., Balsat, M. C., Rogers, H., Fernandez, L. and Hagan, R. M. 1991. Effect of the spirolactam NK-1 receptor antagonist, GR82334, on neurokinin- and electrical stimulation-induced oedema in the rat. $\mathrm{Br}$. J. Pharmacol. 102: 360P.

4. Brain, S. D. and Williams, T. J. 1985. Inflammatory oedema induced by synergism between calcitonin gene-related peptide (CGRP) and mediators of increased permeability. $\mathrm{Br}$. $J$. Pharmacol. 86: 855-860.

5. Brain, S. D., Williams, T. J., Tippins, J. R., Morris, H. R. and MacIntyre, I. 1985. Calcitonin gene-related peptide is a potent vasodilator. Nature (Lond.) 313: 54-56.

6. Buckley, T. L., Brain, S. D., Jose P. J. and Williams, T. J. 1992. The partial inhibition of inflammatory responses induced by capsaicin using the Fab fragment of a selective calcitonin gene-related peptide antiserum in rabbit skin. Neuroscience 48: 963-968.

7. Buckley, T. L., Brain, S. D., Rampart, M. and Williams, T. J. 1991. Time-dependent synergistic interactions between the vasodilator neuropeptide, calcitonin gene-related peptide (CGRP) and mediators of inflammation. Br. J. Pharmacol. 103: 1515-1519.

8. Buckley, T. L., Brain, S. D. and Williams, T. J. 1990. Luthenium red selectively inhibits oedema formation and increased blood flow induced by capsaicin in rabbit skin. $B r . J$. Pharmacol. 99: 7-8.

9. Campbell, E. A., Bevan, S. and Dray, A. 1993. Clinical applications of capsaicin and its analogues. pp. 255-272. In:
Capsaicin in the Study of Pain (Wood, J. N. ed.), Academic, London.

10. Chahl, L. A. 1988. Antidromic vasodilatation and neurogenic inflammation. Pharmacol. Ther. 37: 275-300.

11. Chung, K., Schwen, R. J. and Coggeshall, R. E. 1985. Ureteral axon damage following subcutaneous administration of capsaicin in adult rat. Neurosci. Lett. 53: 221-226.

12. Dickenson, A. H. and Dray, A. 1991. Selective antagonism of capsaicin by capsazepine: evidence for a spinal receptor site in capsaicin-induced antinociception. Br. J. Pharmacol. 104: 1045-1049.

13. Dray, A. 1992a. Mechanism of action of capsaicin-like molecules on sensory neurons. Life Sci. 51: 1759-1765.

14. Dray, A. 1992b. Neuropharmacological mechanisms of capsaicin and related substances. Biochem. Pharmacol. 44: 611-615.

15. Dray, A., Bettaney, J. and Forster, P. 1989. Capsaicin desensitization of peripheral nociceptive fibers does not impair sensitivity to other noxious stimuli. Neurosci. Lett. 99: 50 54.

16. Dray, A., Bettaney, J. and Forster, P. 1990. Actions of capsaicin on peripheral nociceptors of the neonatal rat spinal cord-tail in vitro: dependence of extracellular ions and independence of second messengers. Br. J. Pharmacol. 101: 727-733.

17. Dray, A., Hankins, M. W. and Yeats, J. C. 1989. Desensitization and capsaicin-induced release of substance P-like immunoreactivity from guinea-pig ureter in vitro. Neuroscience 31: 479-483.

18. Dray, A. and Urban, L. 1996. New pharmacological strategies for pain relief. Annu. Rev. Pharmacol. Toxicol. 36: 253-280.

19. Furchgott, R. F. 1984. The role of endothelium in the responses of vascular smooth muscle to drugs. Annu. Rev. Pharmacol. Toxicol. 24: 175-197.

20. Gardiner, S. M., Bennett, T. and O'Neill, T. P. 1989. Synthetic capsaicin reversibly impairs vasopressin-mediated blood pressure recovery. Am. J. Physiol. 257: R1429-R1435.

21. Gardiner, S. M., Compton, A. M., Kemp, P. A. and Bennett, T. 1990. Regional and cardiac haemodynamic effect of $\mathrm{N}^{\mathrm{G}}$ nitro-L-arginine methyl ester in conscious, Long Evans rats. Br. J. Pharmacol. 101: 625-631.

22. Gardiner, S. M., Compton, A. M., Kemp, P. A. and Bennett, T. 1991. Haemodynamic effects of human $\alpha$ calcitonin generelated peptide following administration of endothelin-1 or $\mathrm{N}^{\mathrm{G}}$-nitro-L-arginine methyl ester in conscious rats. $B r . J$. Pharmacol. 103: 1256-1262.

23. Garret, C., Caruette, A., Fardin, V., Moussaoui, S., Peyronel, J-F., Blanchard, J-C. and Laduron, P.M. 1991. Pharmacological properties of a potent and selective nonpeptide substance P antagonist. Proc. Natl. Acad. Sci. U.S.A. 88: 10208-10212.

24. Grace, G. C., Dusting, G. J., Kemp, B. E. and Martin, T. J. 1987. Endothelium and the vasodilator action of rat calcitonin gene-related peptide (CGRP). Br. J. Pharmacol. 91: 729-733.

25. Gray, D. W. and Marshall, I. 1992. Nitric oxide synthesis inhibitors attenuate calcitonin gene-related peptide endothelium-dependent vasorelaxation in rat aorta. Eur. J. Pharmacol. 98: 1080-1082.

26. Green, B. G. 1989. Capsaicin sensitization and desensitization on the tongue produced by brief exposures to a low concentration. Neurosci. Lett. 107: 173-178.

27. Holton, P. and Perry, W. L. M. 1951. On the transmitter 
responsible for antidromic vasodilatation in the rabbit's ear. J. Physiol. (Lond.) 114: 240-251.

28. Holzer, P. 1988. Local effector functions of capsaicin-sensitive sensory nerve endings: involvement of tachykinins, calcitonin gene-related peptide and other neuropeptides. Neuroscience 24: 739-768.

29. Holzer, P. 1991. Capsaicin: Cellular targets, mechanisms of action, and selectivity for thin sensory neurons. Pharmacol. Rev. 43: 143-201.

30. Holzer, P. 1992. Peptidergic sensory neurons in the control of vascular functions: mechanisms and significance in the cutaneous and splanchnic vascular beds. Rev. Physiol. Biochem. Pharmacol. 121: 49-146.

31. Hughes, S. R. and Brain, S. D. 1991. A calcitonin generelated peptide (CGRP) antagonist $\left(\mathrm{CGRP}_{8-37}\right)$ inhibits microvascular responses induced by CGRP and capsaicin in skin. Br. J. Pharmacol. 104: 738-742.

32. Hughes, S. R. and Brain, S. D. 1994. Nitric oxide-dependent release of vasodilator quantities of calcitonin gene-related peptide from capsaicin-sensitive nerves in rabbit skin. $\mathrm{Br}$. $J$. Pharmacol. 111: 425-430.

33. Hughes, S. R., Buckley, T. L. and Brain, S. D. 1992. Olvanil: more potent than capsaicin at stimulating the efferent function of sensory nerves. Eur. J. Pharmacol. 219: 481-484.

34. Hughes, S. R., Williams, T. J. and Brain, S. D. 1990. Evidence that endogenous nitric oxide modulates oedema formation induced by substance P. Eur. J. Pharmacol. 191: 481-484.

35. Kaufman, M. P., Iwamoto, G. A., Longhurst, J. C. and Mitchell, J. H. 1982. Effects of capsaicin and bradykinin on afferent fibers with endings in skeletal muscle. Circ. Res. 50: 133-139.

36. Kenins, P. 1982. Responses of single nerve fibres to capsaicin applied to the skin. Neurosci. Lett. 29: 83-88.

37. Kubota, M., Moseley, J. M., Butera, L., Dusting, G. J., MacDonald, P. S. and Martin, T. J. 1985. Calcitonin generelated peptide stimulates cyclic AMP formation in rat aortic smooth muscle cells. Biochem. Biophys. Res. Commun. 132: 88-94.

38. Lembeck, F., Donnerer, J., Tsuchiya, Y. and Nagahisa, A. 1992. The non-peptide tachykinin antagonist, CP-96,345, is a potent inhibitor of neurogenic inflammation. Br.J. Pharmacol. 105: 527-530.

39. Lembeck, F. and Holzer, P. 1979. Substance P as neurogenic mediator of antidromic vasodilatation and neurogenic plasma extravasation. Naunyn-Schmiedeberg's Arch. Pharmacol. 310: 175-183.

40. Lippe, I. T., Stabentheiner, A. and Holzer, P. 1993. Participation of nitric oxide in the mustard oil-induced neurogenic inflammation of the rat paw skin. Eur. J. Pharmacol. 232: 113-120.

41. Louis, S. M., Jamieson, A., Russell, N. J. W. and Dockray, G. J. 1989. The role of substance P and calcitonin generelated peptide in neurogenic plasma extravasation and vasodilatation in the rat. Neuroscience 32: 581-586.

42. Lynn, B. 1988. Neurogenic inflammation. Skin Pharmacol. 1: 217-224.

43. Marsh, S. J., Stansfeld, C. E., Brown, D. A., Davey, R. and McCarthy, D. 1992. The mechanism of action of capsaicin on sensory C-type neurons and their axons in vitro. Neuroscience 23: 275-289.

44. Maynard, K. I., Saville, V. L. and Burnstock, G. 1990. Sen- sory-motor neuromodulation of sympathetic vasoconstriction in the rabbit central ear artery. Eur. J. Pharmacol. 187: 171182 .

45. Moncada, S., Palmer, R. M. J. and Higgs, E. A. 1991. Nitric oxide: physiology, pathophysiology, and pharmacology. Pharmacol. Rev. 43: 109-142.

46. Moor, P. K., AL-Swayeh, O. A., Chong, N. W. S., Evans, R.

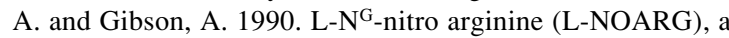
novel, L-arginine-reversible inhibitor of endothelium-dependent vasodilatation in vitro. Br. J. Pharmacol. 99: 408-412.

47. Rees, D. D., Palmer, R. M. J., Schulz, R., Hodson, H. F. and Moncada, S. 1990. Characterization of three inhibitors of endothelial nitric oxide synthase in vitro and in vivo. Br.J. Pharmacol. 101: 746-752.

48. Roberts, R. G. D., Westerman, R. A., Widdop, R. E., Kotzmann, R. R. and Payne, R. 1992. Effects of capsaicin on cutaneous vasodilator responses in humans. Agents Actions 37: 53-59.

49. Schini, L., Katusic, Z. S. and Vanhoutte, P. M. 1990. Neurohypophyseal peptides and tachykinins stimulate the production of cyclic GMP in cultured porcine aortic endothelial cells. $J$. Pharmacol. Exp. Ther. 255: 994-1000.

50. Seno, N. and Dray, A. 1993. Capsaicin-induced activation of fine afferent fibres from rat skin in vitro. Neuroscience 55: 563-569.

51. Suzuki, T., Wada, S., Kobayashi, H. and Tomizawa, N. 1993. Topically applied low concentration of counterirritant, nonylic acid vanillylamide (NVA) dilates rabbit ear artery. Jpn. J. Pharmacol. 61 (Suppl. 1): 225.

52. Suzuki, T., Wada, S., Kobayashi, H. and Tomizawa, N. 1994. Nitric oxide is involved in vasodilatation induced by a topically applied capsaicin congener. Can. J. Physiol. Pharmacol. 72 (Suppl. 1): 475.

53. Suzuki, T., Wada, S., Mashiko, K., Nonaka, K., Kobayashi, H. and Tomizawa, T. 1992. Evaluation of diluted nonylic acid vanillyl amide (NVA) as therapy of circulatory disorder of various tissues: measurement of skin blood flow and temperature in rabbits. Pharmacometrics 44: 627-643 (in Japanese).

54. Szolcsanyi, J. and Jancso-Gabor, A. 1976. Sensory effects of capsaicin congeners. II. Importance of chemical structure and pungency in desensitizing activity of capsaicin-type compounds. Drug Res. 26: 33-37.

55. Szolcsanyi, J., Jancso-Gabor, A. and Joo, F. 1975. Functional and fine structural characteristics of the sensory neuron blocking effect of capsaicin. Naunyn-Schmiedeberg's Arch. Pharmacol. 287: 157-169.

56. Wallengren, J. and Hakanson, R. 1987. Effects of substance $\mathrm{P}$, neurokinin $\mathrm{A}$ and calcitonin gene-related peptide in human skin and their involvement in sensory nerve-mediated responses. Eur. J. Pharmacol. 143: 267-273.

57. Whittle, B. J. R., Lopez-Belmonte, J. and Rees, D. D. 1989. Modulation of the vasodepressor actions of acetylcholine, bradykinin, substance $\mathrm{P}$ and endothelin in the rat by a specific inhibitor of nitric oxide formation. Br.J. Pharmacol. 98: 646-652.

58. Xu, X-J., Hao, J-X., Wiesenfeld-Hallin, Z., Hakanson, R., Folkers, K. and Hokfelt, T. 1991. Spantide II, a novel tachykinin antagonist, and galanin inhibit plasma extravasation induced by antidromic $\mathrm{C}$-fiber stimulation in rat hindpaw. Neuroscience 42: 731-737. 